\title{
Potential autocrine function of vascular endothelial growth factor in head and neck cancer via vascular endothelial growth factor receptor-2
}

\author{
Panayiotis A Kyzas, Dimitrios Stefanou, Anna Batistatou and Niki J Agnantis \\ Department of Pathology, University of Ioannina, Medical School, Ioannina, Greece
}

\begin{abstract}
Vascular endothelial growth factor is a peptide with well-defined actions on the vasculature and fundamental role in tumor angiogenesis. Its action in vascular endothelium is exerted in a paracrine manner. The immunohistochemical expression of this protein by cancer cells in head and neck squamous cell carcinoma was correlated with increased tumor aggressiveness and poor survival in previous studies. In the past years, an increasing amount of studies demonstrated potential autocrine action of vascular endothelial growth factor in various neoplasms. However, the existence and the impact of such autocrine action in head and neck cancer have not been demonstrated yet. In this retrospective study, we evaluated the expression of vascular endothelial growth factor and its receptors in neoplastic cells, in a cohort of patients with head and neck squamous cell carcinoma, and compared this expression with tumor aggressiveness, clinicopathologic parameters and outcome. High expression of vascular endothelial growth factor was strongly correlated with high expression of vascular endothelial growth factor receptor-2 (but not vascular endothelial growth factor receptor-1) on the cancer cells $(P<0.001)$. The co-overexpression of both the protein and vascular endothelial growth factor receptor-2 was associated with higher tumor proliferation rate $(P<0.001)$. The above cooverexpression also correlated with worse survival (log rank $P<0.05)$ in patients with oral-larynx squamous cell carcinoma. Our results suggest that an autocrine vascular endothelial growth factor loop, mediated via vascular endothelial growth factor receptor-2, probably exists in head and neck squamous cell carcinoma. These observations support the hypothesis that the use of vascular endothelial growth factor receptor-2 inhibitors as adjuvant antiangiogenic therapy might have beneficial effects for these patients, by disrupting both paracrine (endothelial-dependent) and autocrine actions of vascular endothelial growth factor.
\end{abstract}

Modern Pathology (2005) 18, 485-494, advance online publication, 8 October 2004; doi:10.1038/modpathol.3800295

Keywords: VEGF; VEGFR-2; VEGFR-1; angiogenesis inhibitors

It is well established that the local growth, and metastatic spread of solid neoplasms is supported by tumor angiogenesis, ${ }^{1,2}$ which refers to a combination of angiogenesis and vasculogenesis. In this process, the main blood supply to a tumor derives from the growth and extension of pre-existing blood vessels (angiogenesis), but circulating endothelial cell precursors may contribute to the growing vascular tree as well (vasculogenesis). ${ }^{3,4}$ In head and neck squamous cell carcinoma, the quantification of tumor angiogenesis by intratumoral micro-

Correspondence: Dr PA Kyzas, DDS, Department of Pathology, University of Ioannina, Medical School, 45110 Ioannina Greece. E-mail:md03791@cc.uoi.gr

Received 9 July 2004; revised and accepted 18 August 2004; published online 8 October 2004 vessel counting correlates with poor clinical outcome,,$^{5,6}$ but results of various studies are conflicting and inconclusive in regard of the size of the estimated risk. ${ }^{7,8}$

A number of putative angiogenic factors such as basic fibroblast growth factor, platelet-derived growth factor, interleukins, and vascular endothelial growth factor (VEGF), are expressed in head and neck squamous cell carcinoma. ${ }^{4}$ VEGF is considered a leading candidate for tumor angiogenesis in head and neck squamous cell carcinoma, exhibiting its effect in the vasculature in a paracrine pattern. ${ }^{1,2}$ This protein binds with high affinity to the tyrosine kinase receptors VEGFR-1 (also known as flt-1) and VEGFR-2 (also known as Flk-1/KDR), which are expressed in endothelial cells during development, wound healing, and in tumor vasculature. ${ }^{9}$ Studies 
examining the association between VEGF immunohistochemical expression and patients' survival in head and neck cancer are more consensus than those examining microvessel density, pointing towards a correlation with poorer overall survival. ${ }^{10-16}$ Also, many studies failed to show association of VEGF expression with higher microvessel density. ${ }^{15,16}$ These aspects raise the possibility that VEGF, which is produced by neoplastic cells, might serve not only for vessel sprouting, but have other functions as well.

Recently, VEGFR-1 and VEGFR-2 expression by tumor cells in melanoma, Kaposi sarcoma and breast cancer, as well as in melanoma, choriocarcinoma and leukemia cell lines was reported. ${ }^{17-24}$ There are also studies describing the existence of VEGF receptors in cancer cell lines and in limited number of tissue samples in head and neck squamous cell carcinoma. $^{25,26}$ These observations suggest that VEGF can function as an autocrine growth factor. This hypothesis was experimentally confirmed both for solid tumors (such as prostate adenocarcinoma) ${ }^{24}$ and also for hematological malignancies (such as acute leukemia). ${ }^{19}$ It is yet unconfirmed whether VEGF exhibits autocrine function in head and neck cancer, and what is the impact of this action, if any.

In the present study, we performed immunohistochemical evaluation of VEGF, VEGFR1 and VEGFR2 expression in 81 primary tumor samples from patients with head and neck squamous cell carcinoma. Our aim was to investigate the presence of co-overexpression of the protein and its receptors; and the possible correlation of this co-overexpression with tumor aggressiveness, clinicopathologic parameters and overall survival of this cohort of patients.

\section{Materials and methods}

\section{Tissues and Clinical Parameters}

A total of 81 paraffin-embedded archival tissue blocks for patients with head and neck squamous cell carcinoma specimens were obtained from the Department of Pathology of the General University Hospital of Ioannina. Of these samples, 68 were also included in our previous study. ${ }^{27}$ Specimens consisted of surgical material obtained from the primary tumor. These patients with head and neck squamous cell carcinoma were treated in the Ear Nose Throat (ENT) Department (Director: Professor A Skevas) of the same hospital, between the years 1998 and 2004. All hematoxylin-eosin-stained sections were reviewed, the quality of the material was checked, and the best section from each specimen was selected. We selected a section showing central and peripheral areas of the tumor (intratumor and peritumor areas), avoiding areas with necrosis. Patient's records were reviewed, and clinicopathological characteristics as well as follow-up data were noted. TNM staging was established by IUCC system, ${ }^{28}$ and grading was performed according to WHO. ${ }^{29}$

\section{Immunohistochemistry}

We performed immunostaining on formalin-fixed, paraffin-embedded tissue sections using EnVision System for monostaining, and additionally, the alkaline phosphatase-labeled procedure for double staining. Seven adjacent $4-\mu \mathrm{m}$-thick sections from each paraffin-embedded block were cut. The first four were used for staining with VEGF, Ki-67, VEGFR-1 and VEGFR-2, respectively, and the rest three were used for double staining for VEGF/Ki-67, VEGF/VEGFR-2 and VEGF/VEGFR-1, respectively.

\section{Monostaining}

For usual staining we used the EnVision System (DAKO) and the monoclonal antibodies VEGF (VEGF Ab-3 JH121, Neomarkers, USA, dilution 1:50), Ki 67 (clone MIB1, DAKO, dilution 1:50), VEGFR-1 (RP 077, DBS, USA, dilution 1:1000) and VEGFR-2 (RP 076, DBS, USA, dilution 1:2000). Sections were at first deparaffinized in xylene and rehydrated through graded concentrations of alcohol. Sections were heated in a microwave oven for 2 circles of $5 \mathrm{~min}$ each, in high $\mathrm{pH}$ buffer (DAKO), for antigen retrieval. Endogenous peroxidase's activity was blocked with $\mathrm{H}_{2} \mathrm{O}_{2}$ solution in methanol $(0.01 \mathrm{M})$, for $30 \mathrm{~min}$. Nonspecific binding was blocked by incubating the sections for $30 \mathrm{~min}$ with serum block (DAKO). After washing with PBS for $5 \mathrm{~min}$, all of the primary antibodies were incubated over night at $4^{\circ} \mathrm{C}$. Then sections were washed for 10 min with PBS. Envision HRP system (DAKO) was used for visualization of the expression of the antibodies. Diaminobenzidinetetrahydrochloride (DAB) was used as a chromogen. All sections were counterstained with hematoxylin.

\section{Double Staining}

The first antibody (Ki-67, VEGFR-2 and VEGFR-1, respectively) was applied as described above. After the visualization of the expression of the antibodies with DAB, sections were washed in PBS for 5 min. Serum block was applied for $5 \mathrm{~min}$ and afterwards, the second antibody (VEGF) was incubated overnight at $4^{\circ} \mathrm{C}$. After washing with PBS for $5 \mathrm{~min}$, secondary antibody (Multilink, Biogenex) was applied for $20 \mathrm{~min}$, followed by $10 \mathrm{~min}$ washing with buffer. Alkaline-phosphatase link (Biogenex) was applied for $20 \mathrm{~min}$, and the expression of the second antibody was visualized with Fast-Red (Biogenex), diluted in naphthol phosphate. One drop of levimazole was added to reduce unspecific background staining. All sections were then counterstained with hematoxylin. 


\section{Antibody Expression}

Two observers (DS and PK) without knowledge of the clinical data performed evaluation of the staining, in the sections with the monostaining. Double staining was used only for the qualitative evaluation of the coexpression pattern. Cell counts were performed only in the sections with monostaining. The percentage of the tumor cells that exhibited a positive immunoreactivity was determined using a $\times 40$ objective lens. At least 1000 neoplastic cells were counted in each case. For VEGF, a cutoff of $20 \%$ cytoplasmic staining in the tumor cells was used to distinguish low from high VEGF-expressing tumors, in order to be in consensus with the majority of the studies performed so far. ${ }^{12-14}$ For Ki-67, nuclear staining was evaluated and a cutoff of $20 \%$ was used to separate tumors with low vs high mitotic rate, as described previously. ${ }^{30,31}$

VEGF receptors are mainly expressed in tumor vasculature $;^{9}$ but their expression in cancer cells was also described. ${ }^{25,26}$ Our aim was to evaluate their expression on the tumor cells, in a quantitative way. The intensity of the membranous-cytoplasmic immunohistochemical staining was evaluated as follows: - , negative, + , focal expression $<5 \%$ of cancer cells, and ++ , diffuse expression $>5 \%$ of cancer cells. Samples with ++ staining were classified as 'high expression group', and those with - and + were assigned as 'low expression group'.

\section{Survival and Recurrence analysis}

The cohort of our patients was divided into two groups regarding the location of the primary tumor. It is well known that squamous cell carcinoma of the lower lip, is more curable than those of the oral cavity or the larynx ${ }^{32}$ and the major problem for this malignancy is local recurrence after surgical removal of the primary tumor. On the other hand, squamous cell carcinoma of the oral cavity and larynx are more aggressive. We performed survival analysis in the subgroup of patients with orallarynx squamous cell carcinoma, and recurrence analysis in the subgroup of patients with squamous cell carcinoma of the lower lip. We also examined whether there was difference in survival rates when the subgroup of patients with oral-larynx squamous cell carcinoma, was further separated to patients with oral squamous cell carcinoma, and patients with larynx squamous cell carcinoma.

\section{Statistical Analysis}

Analyses were conducted in the SPSS software version 11.0. (SPSS, Inc., Chicago, IL, USA). The expression of the antibodies was considered as dichotomous variable using the cutoff value described above. For comparison between variables we used $\chi^{2}$-test. Analyses for survival and recurrence were done using the Kaplan-Meier method and different subgroups were compared using the logrank test. Cox regression model was used to determine the importance of different factors. All differences were considered positive if $P<0.05$. $P$-values are two-tailed.

\section{Results}

\section{Clinicopathological Data}

A total of 81 patients with head and neck squamous carcinoma were included in this retrospective study. The median age of the patients was 65 (range 33-98) years. Of the patients, $63(78 \%)$ were male and 18 $(22 \%)$ were female. In all, 50 of the tumors were located in the lower lip, 22 in the oral cavity and nine in larynx. A total of 21 patients $(26 \%)$ presented with lymph node metastases at the time of diagnosis. Only one of them suffered from lower lip squamous cell carcinoma. Of the patients, 56 $(69 \%)$ had cancer classified as lower (I and II) clinical stage, and 25 (31\%) as high (III and IV). Nine patients $(11 \%)$ had histological high-grade tumors, $51(63 \%)$ had tumors with median differentiation and $21(26 \%)$ of the tumors were well differentiated.

Available follow-up data existed for 28 of the 31 patients with oral-larynx squamous cell carcinoma and for 33 of the 50 patients with lower lip squamous cell carcinoma. Patients were followed up until death or recurrence, respectively, or for at least 24 months. Of the 28 patients with oral-larynx squamous cell carcinoma, 17 were dead at the end of the follow-up period, and 10 of the 33 patients with lip squamous cell carcinoma showed local recurrence.

\section{VEGF Expression}

High VEGF staining in the cytoplasm of the tumor cells was observed in 27 of the 81 tumor samples (33\%). The intensity of immunostaining was often strong, but the staining pattern was heterogeneous (Figure 1a). Some of the inflammatory cells infiltrating the tumors, especially macrophages, were found to stain strongly for VEGF. Weak staining was occasionally observed in vascular endothelium as well.

The correlation of VEGF expression with the expression of its receptors and Ki-67 is summarized in Table 1. High VEGF expression was strongly associated with increased expression of VEGFR-2 $(P<0.001)$, and Ki-67 $(P<0.001)$, but not VEGFR-1 $(P=0.13)$. Of the tumors, 23 presented co-overexpression of both VEGF and VEGFR-2; and all but one of these tumors also presented with high Ki-67 expression $(P<0.001)$. Overexpression of both VEGF and VEGFR-1 was observed only in 12 tumor samples; and for these tumors, the correlation with 

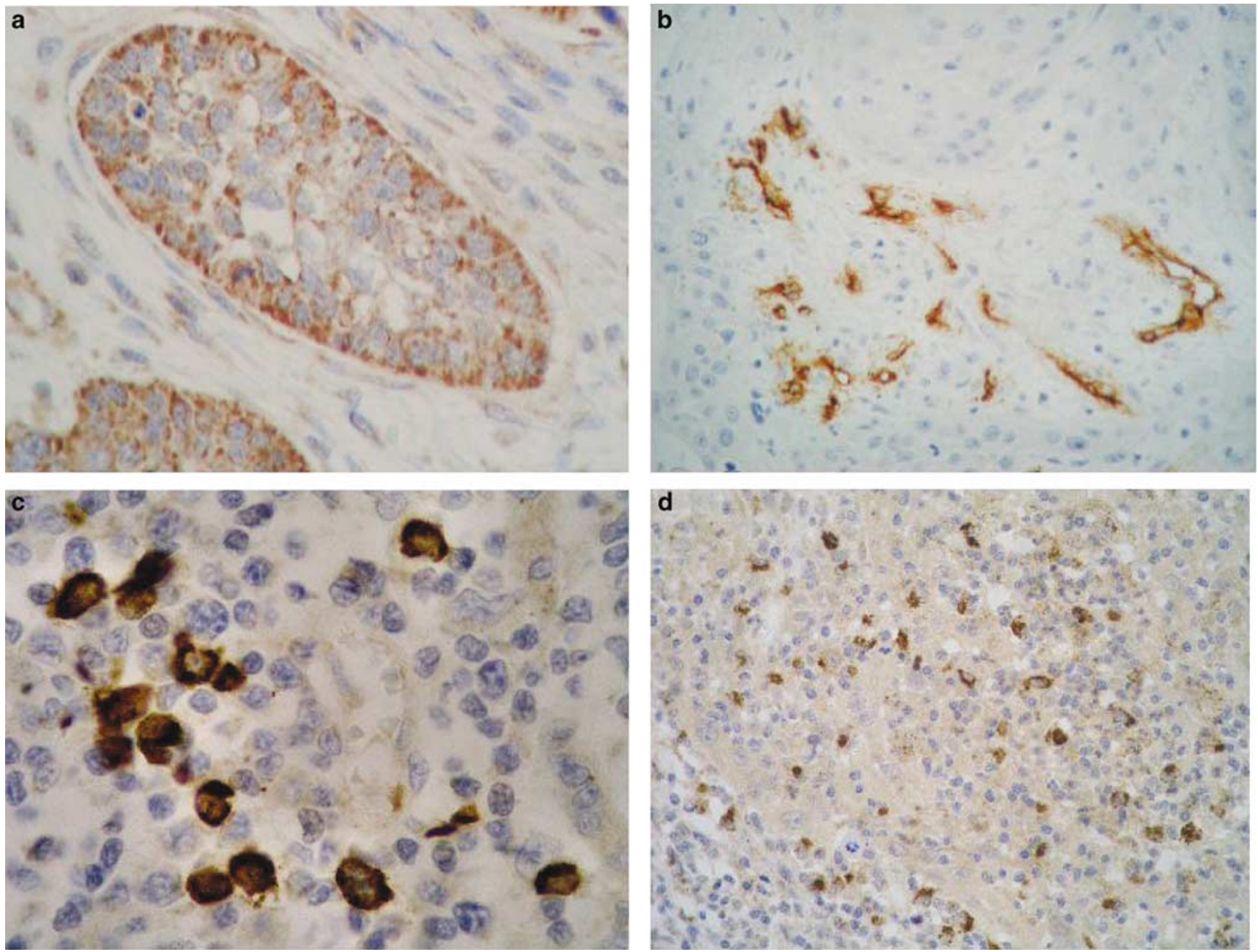

Figure 1 (a) Diffuse cytoplasmic VEGF immunoreactivity in cancer cells in a laryngeal carcinoma (magnification $\times 400)$. (b) VEGFR-2 expression in vascular endothelium in squamous cell carcinoma of the floor of the mouth (magnification $\times 200)$. (c and d) Membranouscytoplasmic expression of VEGFR-2 in cancer cells in squamous cell carcinoma of the tongue (magnification $\times 1000$ and $\times 200$, respectively). (e) VEGFR-1 expression in vascular endothelium in squamous cell carcinoma of the floor of the mouth (magnification $\times 400$ ). (f) Membranous-cytoplasmic expression of VEGFR-1 in cancer cells in squamous cell carcinoma of the tongue (magnification $\times 200$ ). (g) and (h) Intense nuclear immunostaining with proliferation marker Ki-67 in squamous cell carcinoma of the larynx (magnification $\times 1000$ and $\times 400$, respectively).

Ki-67 overexpression was not formally significant $(P=0.055)$.

There was no statistically significant correlation between VEGF expression and age, sex, histological grade and lymph node status. On the other hand, high VEGF expression was correlated with a higher clinical stage $(P=0.04)$. High VEGF expression was very rare in tumors located in the lower lip; whereas tumors located in the oral cavity and larynx more often expressed high VEGF immunostaining $(P=0.03)$. There was no difference in VEGF expression between tumors located in the oral cavity from those located in larynx (Table 2).

\section{VEGFR-2 Expression}

Intracytoplasmic and membrane staining in tumor endothelium was observed in all of the samples, but the intense of the staining was heterogeneous and often weak (Figure 1b). Surprisingly, intense cytoplasmic and membrane staining was present in tumor cells in 46 out of the 81 samples (57\%) (Figure 1c,d), and in some cases staining was very strong. As mentioned above, there was a strong association of VEGFR-2 overexpression with high VEGF and Ki-67 expression, and an impressive correlation of the co-overexpression of VEGF and VEGFR-2 with Ki-67.

Association of VEGFR-2 expression with clinicopathologic parameters followed the same pattern as VEGF expression; that is absence of any significant association of its expression with age, sex, histological grade and lymph node status, whereas a strong correlation was observed for higher clinical stage $(P=0.02)$ and for tumors located in the oral cavity and larynx $(P=0.001)$. 

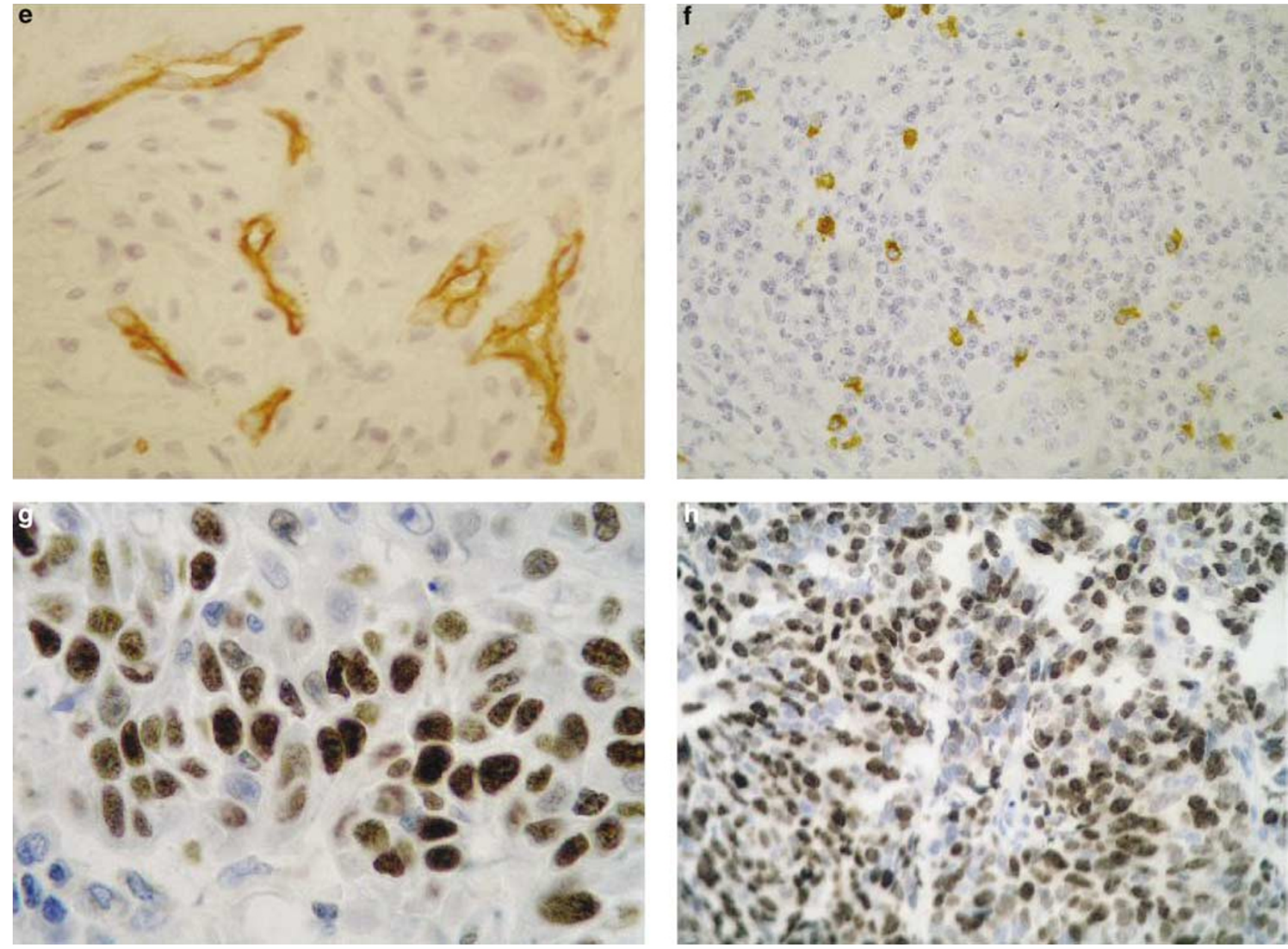

Figure 1 Continued.

Table 1 Correlation between the expression of the four (VEGF, VEGFR-1, VEGFR-2 and Ki-67) antibodies used for immunohistochemistry

\begin{tabular}{|c|c|c|c|c|c|c|c|c|c|c|c|c|c|}
\hline & & \multicolumn{3}{|c|}{$V E G F$} & \multicolumn{3}{|c|}{ VEGFR-1 } & \multicolumn{3}{|c|}{ VEGFR-2 } & \multicolumn{3}{|c|}{$K i-67$} \\
\hline & & High & Low & $\mathrm{P}$-value & High & Low & $\mathrm{P}$-value & High & Low & $\mathrm{P}$-value & High & Low & $\mathrm{P}$-value \\
\hline \multirow[t]{2}{*}{ VEGFR-1 } & High & 12 & 15 & NS & & & & & & & & & \\
\hline & Low & 15 & 39 & & & & & & & & & & \\
\hline \multirow[t]{2}{*}{ VEGFR-2 } & High & 23 & 23 & $<0.001$ & 25 & 21 & $<0.001$ & & & & & & \\
\hline & Low & 4 & 31 & & 2 & 33 & & & & & & & \\
\hline \multirow[t]{2}{*}{ Ki-67 } & High & 23 & 21 & $<0.001$ & 19 & 25 & NS & 38 & 6 & $<0.001$ & & & \\
\hline & Low & 4 & 33 & & 8 & 29 & & 8 & 29 & & & & \\
\hline VEGF/ & Yes & & & & 12 & 11 & NS & & & & 22 & 1 & $<0.001$ \\
\hline VEGFR-2 & No & & & & 15 & 43 & & & & & 22 & 36 & \\
\hline
\end{tabular}

NS: nonsignificant.

\section{VEGFR-1 Expression}

The cell-staining pattern was the same as VEGFR-2 (intracytoplasmic and membranous), with hetero- geneous expression in tumor vasculature (Figure 1e). The overexpression of VEGFR-1 by tumor cells was not as frequent as for VEGFR-2; it was observed in 27 of the tumor samples (33\%) (Figure 1f). 
Table 2 Correlation between the expression of VEGF and VEGFR-2 and the clinicopathological characteristics of the patients

\begin{tabular}{|c|c|c|c|c|c|c|c|}
\hline & & \multicolumn{3}{|c|}{$V E G F$} & \multicolumn{3}{|c|}{ VEGFR-2 } \\
\hline & & High & Low & $\mathrm{P}$-value & High & Low & $\mathrm{P}$-value \\
\hline \multirow[t]{3}{*}{ Location } & Oral & 10 & 12 & \multirow[t]{3}{*}{0.03} & 16 & 6 & \multirow[t]{3}{*}{0.001} \\
\hline & Larynx & 5 & 4 & & 8 & 1 & \\
\hline & Lower lip & 12 & 38 & & 22 & 28 & \\
\hline \multirow[t]{3}{*}{ Histological grade } & Low & 3 & 6 & \multirow[t]{3}{*}{ NS } & 5 & 4 & \multirow[t]{3}{*}{ NS } \\
\hline & Medium & 16 & 35 & & 27 & 23 & \\
\hline & High & 8 & 13 & & 14 & 7 & \\
\hline \multirow[t]{2}{*}{ Survival at 24 months (oral, larynx) } & Dead & 12 & 5 & \multirow[t]{2}{*}{0.03} & 14 & 3 & \multirow[t]{2}{*}{0.04} \\
\hline & Alive & 5 & 8 & & 4 & 9 & \\
\hline
\end{tabular}

NS: nonsignificant.

No association was observed between VEGFR-1 expression and age, sex, histological grade, lymph node status and clinical stage, whereas tumors located in the oral cavity and larynx, presented more often with VEGFR-1 overexpression $(P=0.02)$.

\section{Ki-67 (MIB-1) Expression}

Intense nuclear staining of the proliferation marker Ki-67 was observed in 44 of the tumor samples $(54 \%)$ (Figure 1g, h), and its presence was associated with a more aggressive tumor profile, including higher clinical stage $(P=0.01)$ and the presence of lymph node metastasis at the time of diagnosis $(P=0.004)$.

\section{Double Immunostaining}

The statistically addressed co-overexpression of VEGF/VEGFR-2, and VEGF/Ki-67 in tumor samples was confirmed by double immunostaining (Figure 2). The double staining pattern was quite similar for VEGF/VEGFR-2 and VEGF/Ki-67 expression respectively (Figure $2 \mathrm{~h}-\mathrm{j}$ ). We observed cancer cells that were spontaneously expressing VEGF, VEGFR-2 and Ki-67 (Figure 2a,b). Also, cells in the same tumor area were expressing either VEGF or VEGFR-2 (Figure 2l). For some samples, expression of both VEGF and Ki-67 was more than $75 \%$ of the tumor cells (Figure $2 \mathrm{~h}, \mathrm{k}$ ). Immunoreactivity for VEGFR-1 was located in different and independent tumor areas than VEGF and no agreement with VEGF/Ki67 double staining pattern was observed.

\section{Survival and Recurrence Analysis}

VEGF expression, VEGFR-2 overexpression and VEGF/VEGFR-2 co-overexpression were correlated with worse survival in the group of patients with oral and larynx squamous cell carcinoma (in all cases log rank $P<0.05$ ). There was also a trend towards an association of the presence of lymph nodes at the time of diagnosis with worse survival $(P=0.08)$. No association was observed between clinical stage, histological grade, Ki-67 expression and VEGFR-1 expression with overall survival. The small number of patients did not allow us to run Cox regression model to determine the importance of the three different potential prognostic variables. ${ }^{33}$ Kaplan-Meier analyses showed the same results for the above factors, when the group was further separated in patients with oral and larynx squamous cell carcinoma respectively (log rank $P<0.05$, for all three factors).

As we found in a previous study, ${ }^{34}$ VEGF overexpression was the only independent prognostic factor for recurrence in patients with squamous cell carcinoma of the lower lip (log rank $P<0.001$ ). No one from the currently examined markers (Ki-67, VEGFR-2 and VEGFR-1) was correlated with recurrence in these patients.

Figure 2 (a) Double immunostaining with VEGF (red) and Ki-67 (brown) in squamous cell carcinoma of the tongue. The same cancer cell expresses the two markers (magnification $\times 1000$ ). (b) The same tumor sample as in (a), in an adjacent section. VEGFR-2 (brown) and VEGF (red) are expressed in the same cancer cell (magnification $\times 1000)$. (c) Expression of both VEGF and VEGFR-2 in the same cells in squamous cell carcinoma of the floor of the mouth. There are also cells expressing either VEGF or VEGFR-2 (magnification $\times 200)$. (d-f) Double immunostaining with VEGF (red) and Ki-67 (brown) in squamous cell carcinoma of the larynx. The same cancer cells express both the two markers (magnification $\times 1000, \times 1000$ and $\times 400$, respectively). (g-k) Double immunostaining with VEGF (red) and Ki-67 (brown) in squamous cell carcinoma of the tongue $(\mathbf{g}-\mathbf{j})$ and larynx $(\mathbf{k})$. We can see overexpression of both of the markers in a high percentage of the tumor cells. (l) Expression of both VEGF and VEGFR-2 in the same cells in squamous cell carcinoma of the lower lip. Tumor cells in the same tumor area express either VEGF or VEGFR-2 (magnification $\times 400$ ). 

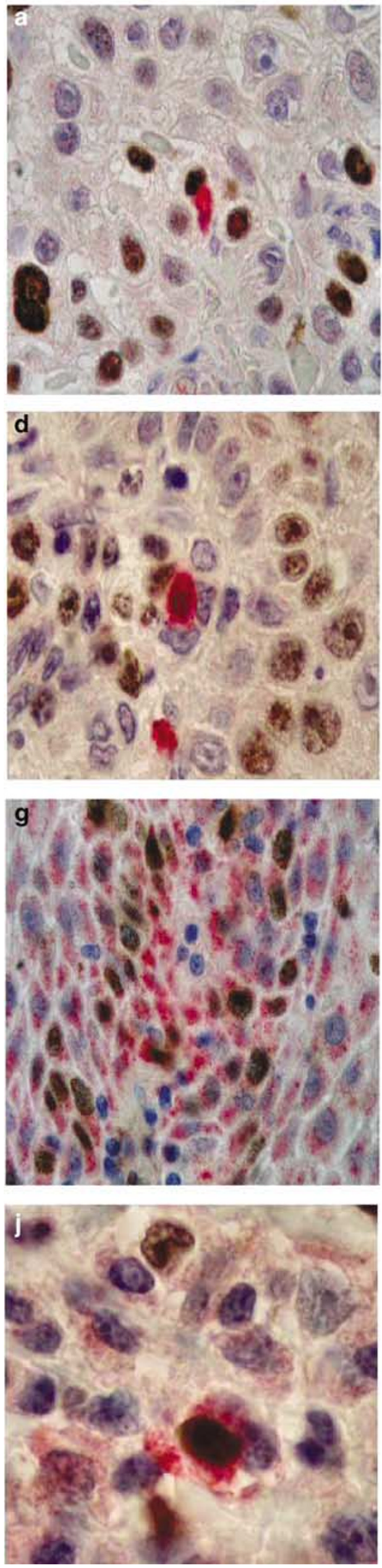
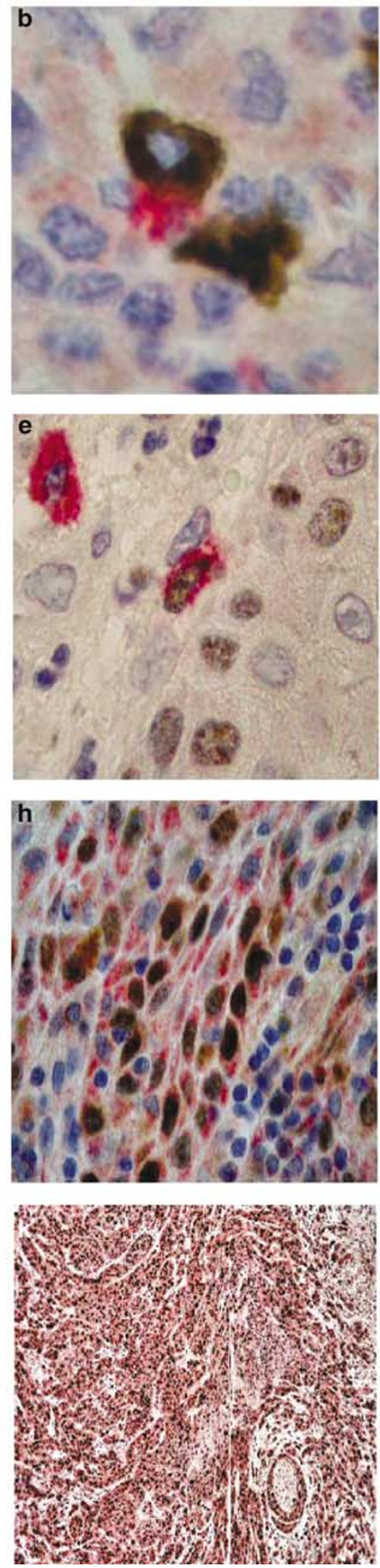
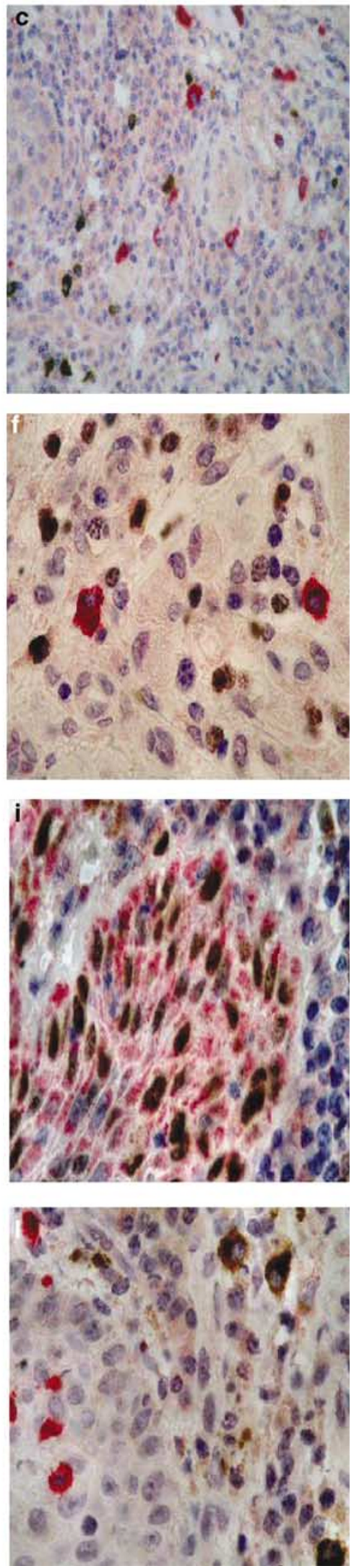


\section{Discussion}

Among all the known angiogenic growth factors, VEGF plays a paramount and indispensable role in regulating the multistep process of tumor angiogenesis. $^{1-4}$ This protein induces the proliferation, differentiation, and migration of vascular endothelial cells, ${ }^{4,35}$ increases the permeability of the capillaries, ${ }^{1,35}$ and also enhances the survival of endothelial cells by preventing their apoptosis. ${ }^{36}$ However, it is quite possible that its action is not limited in the paracrine, endothelial dependent, angiogenic pathway, but also extends towards a potential autocrine action between cancer cells in various malignancies. ${ }^{19-24}$

VEGF activities are mediated via two tyrosine kinase receptors VEGFR-1 (also known as flt-1) and VEGFR-2 (also known as Flk-1/KDR). Although VEGF binds with VEGFR-1 with higher affinity, it is well known that mitogenic and proliferating actions of VEGF in endothelial cells are mediated via VEGFR-2. ${ }^{9}$ Activation of VEGFR-1 by VEGF in endothelial cells lacking VEGFR-2 does not induce cell proliferation. ${ }^{9}$ VEGFR-1 plays an important role in modulating the activities of VEGFR-2 $2^{37,38}$ and the circulating levels of VEGF, in regulating extracellular matrix proteolytic activity, ${ }^{39}$ and in controlling the release of nitric oxide by endothelial cells. ${ }^{9}$ These aspects are mainly due to the different signal transduction cascades induced by VEGFR-1 and VEGFR-2; and specifically, for cell proliferation, to the activation of mitogen-activated protein kinase (MAPK) only by VEGFR-2. ${ }^{36}$ It is therefore conceivable that the potential autocrine action of VEGF is mediated via VEGFR-2.

The most interesting finding in our study is the co-overexpression of VEGF and (VEGFR-2) in head and neck squamous cell carcinoma cells. We have also demonstrated a strong association of VEGF/ VEGFR-2 overexpression with a higher cell proliferation rate, as determined by Ki-67 overexpression. These aspects are clear hints towards the existence of a VEGF autocrine loop, in squamous carcinoma. Patients with oral and larynx squamous cell carcinoma exhibited worse survival rates when there was co-overexpression of VEGF and VEGFR-2. Also, this co-overexpression was correlated with higher clinical stage. Tumors located in the lower lip demonstrated VEGF/VEGFR-2 overexpression very rarely, and this might offer a logical explanation for their decreased aggressiveness. In our previous work, ${ }^{34}$ we found that VEGF overexpression was the only independent prognostic factor for recurrence in patients with squamous cell carcinoma of the lower lip (log rank $P<0.001$ ), and these results were confirmed by the current study. No one from the currently examined markers (Ki-67, VEGFR-2 and VEGFR-1) was correlated with recurrence in these patients. Only four of these patients had co-overexpression of VEGF and VEGFR-2, and no association with recurrence was observed for this co-overexpression. However, this can be spurious due to the very limited number of the patients with VEGF/VEGFR-2 co-overexpression.

The above observations indicate that a potential autocrine function of VEGF may increase VEGFrelated tumor aggressiveness. Previous reports ${ }^{25,26}$ demonstrated the existence of VEGF receptors in head and neck squamous cell carcinoma cells, along with a predominant overexpression of VEGFR-2. This is in agreement with our results. Double staining confirmed the statistically addressed associations and revealed the colocalization of VEGF and VEGFR-2 in cancer cells, and occasionally the expression of all three of VEGF/VEGFR-2/Ki-67, in the same cell. Also, the expression of either VEGF or VEGFR-2 in cancer cells located in the same tumor area, suggests the existence of a paracrine (endothelial-independent) loop between cancer cells. Similar paracrine action between cancer cells and stromal cells that infiltrate the tumor was previously described. ${ }^{26}$

Some limitations of our study should be discussed. First, the sample size is limited and does not allow the performance of multivariate analysis. ${ }^{33}$ Such an analysis would have confirmed observations of the univariate analysis for the predictive ability of VEGF and VEGFR-2 co-overexpression on the patients' outcome and on the aggressive behavior of the tumors. Second, the co-overexpression of the protein and its receptor was not observed in all of the tumor samples; and thus, a potential autocrine action of VEGF might not be a general property of head and neck squamous cell carcinoma.

VEGF/VEGFR-2 autocrine pathway was proposed and confirmed in vitro for other malignancies. ${ }^{19,24}$ On the other hand, it is reported that VEGF stimulates DNA synthesis in choriocarcinoma cell lines, which express both VEGFR-1 and VEGFR-2. ${ }^{23}$ VEGF autocrine activity was also described in benign neoplasms, such as cardiac myxomas, which also express both receptors. ${ }^{40}$ We observed VEGFR-1 expression in neoplastic cells in our samples, but its expression was correlated neither with VEGF nor with Ki-67 expression. Thus, autocrine VEGF pathways are not yet completely understood, and probably there are differences in the manifestation between various neoplasms. However, it is quite possible that VEGF autocrine action is an enhancer of uncontrolled tumor proliferation and along with tumor angiogenesis regulates tumor metastatic potential, increasing tumor aggressiveness.

Understanding autocrine faction of VEGF and cross talks between autocrine and paracrine pathways will help to the development of new therapeutic strategies, and to the critical evaluation of the usefulness of the currently used antiangiogenic agents. A fundamental approach to inhibit angiogenesis during tumorigenesis is the disruption of VEGF/VEGFR-2 pathway. ${ }^{41}$ This could suppress tumor growth by limiting their blood supply, by changing the morphology, wall structure and 
function of tumor vasculature to a more normal fashion, ${ }^{42}$ and thus improving drug penetration in tumors, and also by blocking VEGF autocrine pathway and thus reducing uncontrolled neoplastic cell proliferation.

Currently, a lot of VEGFR-2 inhibitors are undergoing preclinical and clinical evaluation. ${ }^{41}$ The most studied is SU5416 (semaxanib), which also presents inhibitory activity towards VEGFR-1. Studies in mice with transgenic prostate adenocarcinoma (TRAMP model) ${ }^{43}$ revealed a significant decrease in intratumor microvessel density, an increment in cancer cell's apoptotic index, and pronounced regions of cell death. However, these observations were not confirmed by a recently performed phase II trial. ${ }^{44}$ Although initial results from clinical trials in acute leukemia ${ }^{45}$ showed a favorable outcome for patients taking SU5416, results from phase II studies for melanoma, ${ }^{46}$ multiple myeloma, ${ }^{47}$ and renal cancer $^{48}$ diminish original enthusiasm. No clinical trial has been performed so far regarding the efficacy of VEGFR-2 inhibitors as adjuvant chemotherapy in patients with head and neck cancer. Results of clinical trials are necessary for the design of future kinase inhibitors, and observations like the above described, for possible autocrine VEGF/VEGFR-2 pathway in head and neck cancer, provides an additional reason (besides the antiangiogenic effect) of the potential usefulness of these agents. The field of the antiangiogenic therapy remains open to debate concerning the efficacy and tolerability of the antigenic agents, and the spectra of malignancies, which might have the maximal benefit from this therapeutic strategy.

In conclusion, this study demonstrates that an autocrine VEGF loop, mediated via VEGFR-2, probably exists in head and neck squamous cell carcinoma. This aspect, combined with the wellknown angiogenic effects of VEGF, increases VEGF-related tumor aggressiveness. The above observations, in association with the results of previous reports, may lay the foundation for a different therapeutic approach, in which patients with VEGF-producing, VEGR-2-expressing head and neck cancer, may receive adjuvant antiangiogenic therapy, based on VEGFR-2 inhibitors, alone or in combination with currently used chemotherapy.

\section{References}

1 Folkman J. Angiogenesis in cancer, vascular, rheumatoid and other disease. Nat Med 1995;1:27-31.

2 Ferrara N, Davis-Smith T. The biology of vascular endothelial growth factor. Endocrin Rev 1997;18:4-25.

3 Ellis LM, Liu W, Fan F, et al. Role of angiogenesis inhibitors in cancer treatment. Oncology (Huntingt) 2001;15:39-46.

4 Reinmuth N, Parikh AA, Ahmad SA, et al. Biology of angiogenesis in tumors of the gastrointestinal tract. Microsc Res Techn 2003;60:199-207.
5 Shpitzer T, Chaimoff M, Gal R, et al. Tumor angiogenesis as a prognostic factor in early oral tongue cancer. Arch Otolaryngol Head Neck Surg 1996;122:865-868.

6 Pazouki S, Chisholm DM, Adi MM, et al. The association between tumour progression and vascularity in the oral mucosa. J Pathol 1997;183:39-43.

7 Dray TG, Hardin NJ, Sofferman RA. Angiogenesis as a prognostic marker in early head and neck cancer. Ann Otol Rhinol Laryngol 1995;104:724-729.

8 Gleich LL, Biddinger PW, Pavelic ZP, et al. Tumor angiogenesis in T1 oral cavity squamous cell carcinoma: role in predicting tumor aggressiveness. Head Neck 1996;18:343-346.

9 Neufeld G, Cohen T, Gengrinovitch S, et al. Vascular endothelial growth factor (VEGF) and its receptors. FASEB J 1999;13:9-22.

10 Salven P, Heikkila P, Anttonen A, et al. Vascular endothelial growth factor in squamous cell head and neck carcinoma: Expression and prognostic significance. Mod Pathol 1997;10:1128-1133.

11 Maeda T, Matsumura S, Hiranuma H, et al. Expression of vascular endothelial growth factor in human oral squamous cell carcinoma: its association with tumour progression and p53 gene status. J Clin Pathol 1998;51: $771-775$.

12 Smith BD, Smith GL, Carter D, et al. Prognostic significance of vascular endothelial growth factor protein levels in oral and oropharyngeal squamous cell carcinoma. J Clin Oncol 2000;18:2046-2052.

13 Aebersold DM, Beer KT, Laissue J, et al. Intratumoral microvessel density predicts local treatment failure of radically irradiated squamous cell cancer of the oropharynx. Int J Radiat Oncol Biol Phys 2000;48: 17-25.

14 Gallo O, Franchi A, Magnelli L, et al. Cyclooxygenase2 pathway correlates with VEGF expression in head and neck cancer: implications for tumor angiogenesis and metastasis. Neoplasia 2001;3:53-61.

15 Moriyama M, Kumagai S, Kawashiri S, et al. Immunohistochemical study of tumor angiogenesis in oral squamous cell carcinoma. Oral Oncol 1997;33: 369-374.

16 Artese L, Rubini C, Ferrero G, et al. Microvessel density (MVD) and vascular endothelial growth factor expression (VEGF) in human oral squamous cell carcinoma. Anticancer Res 2001;21:689-696.

17 Masood R, Cai J, Zheng T, et al. Vascular endothelial growth factor/vascular permeability factor is an autocrine growth factor for AIDS-Kaposi sarcoma. Proc Natl Acad Sci USA 1997;94:979-984.

18 Masood R, Cai J, Zheng T, et al. Vascular endothelial growth factor (VEGF) is an autocrine growth factor for VEGF receptor-positive human tumors. Blood 2001;98: 1904-1913.

19 Dias S, Hattori K, Heissig B, et al. Inhibition of both paracrine and autocrine VEGF/VEGFR-2 signaling pathways is essential to induce long-term remission of xenotransplanted human leukemias. Proc Natl Acad Sci USA 2001;98:10857-10862.

20 Ryden L, Linderholm B, Nielsen NH, et al. Tumor specific VEGF-A and VEGFR2/KDR protein are coexpressed in breast cancer. Breast Cancer Res Treat 2003;82:147-154.

21 Herold-Mende C, Steiner HH, Andl T, et al. Expression and functional significance of vascular endothelial growth factor receptors in human tumor cells. Lab Invest 1999;79:1573-1582. 
22 Straume O, Akslen LA. Increased expression of VEGFreceptors (FLT-1, KDR, NRP-1) and thrombospondin-1 is associated with glomeruloid microvascular proliferation, an aggressive angiogenic phenotype, in malignant melanoma. Angiogenesis 2003;6:295-301.

23 Charnock-Jones DS, Sharkey AM, Boocock CA, et al. Vascular endothelial growth factor receptor localization and activation in human trophoblast and choriocarcinoma cells. Biol Reprod 1994;51:524-530.

24 Jackson MW, Roberts JS, Heckford SE, et al. A potential autocrine role for vascular endothelial growth factor in prostate cancer. Cancer Res 2002;62:854-859 (Erratum in: Cancer Res 2000;62:2200).

25 Lalla RV, Boisoneau DS, Spiro JD, et al. Expression of vascular endothelial growth factor receptors on tumor cells in head and neck squamous cell carcinoma. Arch Otolaryngol Head Neck Surg 2003;129:882-888.

26 Neuchrist C, Erovic BM, Handisurya A, et al. Vascular endothelial growth factor $\mathrm{C}$ and vascular endothelial growth factor receptor 3 expression in squamous cell carcinomas of the head and neck. Head Neck 2003; 25:464-474.

27 Kyzas PA, Stefanou D, Agnantis NJ. COX-2 expression correlates with VEGF-C and lymph node metastasis in patients with head and neck squamous cell carcinoma. Mod Pathol 2004; Epub ahead of print.

28 Sobin LH, Wittekind C (eds). TNM Classification of Malignant Tumours, 5th edn. UICC. Wiley-Liss: New York, 1997.

29 Coindre JM, Blanc-Vincent MP, Collin F, et al. 2001 Standards, Options and Recommendations: practice guidelines for difficult diagnoses in surgical pathology or cytopathology in cancer patients. Ann Pathol 2003; 23:460-470.

30 Raybaud H, Fortin A, Bairati I, et al. Nuclear DNA content, an adjunct to p53 and Ki-67 as a marker of resistance to radiation therapy in oral cavity and pharyngeal squamous cell carcinoma. Int J Oral Maxillofac Surg 2000;29:36-41.

31 Grabenbauer GG, Muhlfriedel C, Rodel F, et al. Squamous cell carcinoma of the oropharynx: Ki-67 and p53 can identify patients at high risk for local recurrence after surgery and postoperative radiotherapy. Int J Radiat Oncol Biol Phys 2000;48:1041-1050.

32 Hong WK, Lippman SM, Itri LM, et al. Prevention of second primary tumors with isotretinoin in squamouscell carcinoma of the head and neck. N Engl J Med 1990;323:795-801.

33 Concato J, Feinstein AR, Holford TR. The risk of determining risk with multivariable models. Ann Intern Med 1993;118:201-210.

34 Kyzas AP, Stefanou D, Agnantis NJ. Immunohistochemical expression of vascular endothelial growth factor correlates with positive surgical margins and recurrence in $\mathrm{T} 1$ and $\mathrm{T} 2$ squamous cell carcinoma (SCC) of the lower lip. Oral Oncol 2004;40:941-947.

35 Breslin JW, Pappas PJ, Cerveira JJ, et al. VEGF increases endothelial permeability by separate signal- ing pathways involving ERK-1/2 and nitric oxide. Am J Physiol Heart Circul Physiol 2003;284:92-100.

36 Gupta K, Kshirsagar S, Li W, et al. VEGF prevents apoptosis of human microvascular endothelial cells via opposing effects on MAPK/ERK and SAPK/JNK signalling. Exp Cell Res 1999;247:495-504.

37 Roberts DM, Kearney JB, Johnson JH, et al. The vascular endothelial growth factor (VEGF) receptor Flt-1 (VEGFR-1) modulates Flk-1 (VEGFR-2) signaling during blood vessel formation. Am J Pathol 2004;164: 1531-1535.

38 Yamane A, Seetharam L, Yamaguchi S, et al. A new communication system between hepatocytes and sinusoidal endothelial cells in liver through vascular endothelial growth factor and Flt tyrosine kinase receptor family (Flt-1 and KDR/Flk-1). Oncogene 1994; 9:2683-2690.

39 Wang H, Keiser JA. Vascular endothelial growth factor upregulates the expression of matrix metalloproteinases in vascular smooth muscle cells: role of flt-1. Circ Res 1998;83:832-840.

40 Sakamoto H, Sakamaki T, Kanda T, et al. Vascular endothelial growth factor is an autocrine growth factor for cardiac myxoma cells. Circ J 2004;68:488-493.

41 Underiner TL, Ruggeri B, Gingrich DE. Development of vascular endothelial growth factor receptor (VEGFR) kinase inhibitors as anti-angiogenic agents in cancer therapy. Curr Med Chem 2004;11:731-745.

42 Tong RT, Boucher Y, Kozin SV, et al. Vascular normalization by vascular endothelial growth factor receptor 2 blockade induces a pressure gradient across the vasculature and improves drug penetration in tumors. Cancer Res 2004;64:3731-3736.

43 Huss WJ, Barrios RJ, Greenberg NM. SU5416 selectively impairs angiogenesis to induce prostate cancerspecific apoptosis. Mol Cancer Ther 2003;2:611-616.

44 Stadler WM, Cao D, Vogelzang NJ, et al. A randomized Phase II trial of the antiangiogenic agent SU5416 in hormone-refractory prostate cancer. Clin Cancer Res 2004;10:3365-3370.

45 Fiedler W, Mesters R, Tinnefeld H, et al. A phase 2 clinical study of SU5416 in patients with refractory acute myeloid leukemia. Blood 2003;102:2763-2767. Epub 2003 Jul 03.

46 Peterson AC, Swiger S, Stadler WM, et al. Phase II study of the Flk-1 tyrosine kinase inhibitor SU5416 in advanced melanoma. Clin Cancer Res 2004;10: 4048-4054.

47 Zangari M, Anaissie E, Stopeck A, et al. Phase II study of SU5416, a small molecule vascular endothelial growth factor tyrosine kinase receptor inhibitor, in patients with refractory multiple myeloma. Clin Cancer Res 2004;10:88-95.

48 Lara Jr PN, Quinn DI, Margolin K, et al. SU5416 plus interferon alpha in advanced renal cell carcinoma: a phase II California Cancer Consortium Study with biological and imaging correlates of angiogenesis inhibition. Clin Cancer Res 2003;9:4772-4781. 